\title{
P-31 Magnetic Resonance Spectroscopy. A tool for diagnostic purposes and pathophysiological insights in muscle diseases
}

\author{
Spettroscopia di risonanza magnetica P-31. \\ Uno strumento utile ai fini diagnostici \\ e per le indagini fisiopatologiche nelle malattie muscolari
}

\author{
J.P. Mattei, D. Bendahan, P. Cozzone \\ Centre de Résonance Magnétique Biologique et Médicale, (CRMBM, UMR-CNRS 6612), \\ Faculté de Médecine, 27 Bd Jean Moulin, 13005 Marseille, France
}

\begin{abstract}
RIASSUNTO
La spettroscopia di risonanza magnetica (SRM) P-31 è un potente mezzo di indagine che permette di studiare le possibilità energetiche muscolari nell'uomo in maniera non invasiva. Questa rassegna descrive il contributo della SRM P-31 nella diagnosi delle miopatie metaboliche e suggerisce alcuni aspetti chiave per il suo utilizzo clinico. Viene inoltre sottolineato il contributo della SRM P-31 nello studio della fisiopatologia di diverse altre malattie.
\end{abstract}

Reumatismo, 2004; 56(1):9-14

\begin{abstract}
t has been more than 15 years since 31-phosphorus magnetic resonance spectroscopy $\left({ }^{31} \mathrm{P}-\mathrm{MRS}\right)$ was first used in order to study human muscle diseases. Its impact on the field of neuromuscular disorders has now become considerable for pathophysiological insights and for diagnostic purposes. Recent reviews (1-3) have summarized the possibilities of the technique that permits to investigate muscle energetic metabolism non-invasively and non-destructively. In this mini-review, we will recall the information provided by a P-31 MRS spectrum when exploring a normal muscle and present the new spectral semiology that is helpful for the diagnosis of metabolic myopathies. We will also show briefly some other clinical applications of this technique.
\end{abstract}

\section{P-31 MRS}

MRS is a nuclear magnetic resonance technique that has been adapted for acquiring biochemical in-

\footnotetext{
Indirizzo per la corrispondenza:

Dott. Jean-Pierre Mattei

Centre de Résonance Magnétique Biologique et Médicale

Faculté de Médecine, 27 Bd Jean Moulin, 13005 Marseille, France

E-mail: matteijp@club-internet.fr
}

formation in vivo from a defined volume of tissue. Different kinds of magnet have been used to investigate human muscle, depending on the anatomic area of interest. The intensity of the magnetic field varies greatly (from 1 to 4,7 teslas) from study to study, the spectral definition being better when using higher magnetic field intensity. The muscle examined is generally positioned in the center of the magnet, in a fixed position and a surface coil is placed next to the area of interest and used as both $\mathrm{RF}$ transmitter and receiver. Coil size and position as well as pulsing conditions determine the location and size of the volume of muscle interrogated.

Muscle is in many ways an ideal tissue for MRS studies because it can be stressed in the magnet with exercise while the biochemical response is monitored. P-31 MRS records signals from highenergy phosphate compounds which are central to energy metabolism in vivo. Phosphorus MR spectra from muscle (Fig. 1) contain seven resonance: three arise from the phosphate groups of adenosine triphosphate (ATP), one from phosphocreatine $(\mathrm{PCr})$ and one from inorganic phosphates $(\mathrm{Pi})$; two additional smaller resonances can sometimes be observed from phosphomonoesters (PME) and phosphodiesters (PDE). The area under each resonance (i.e., the signal intensity) is proportional to 


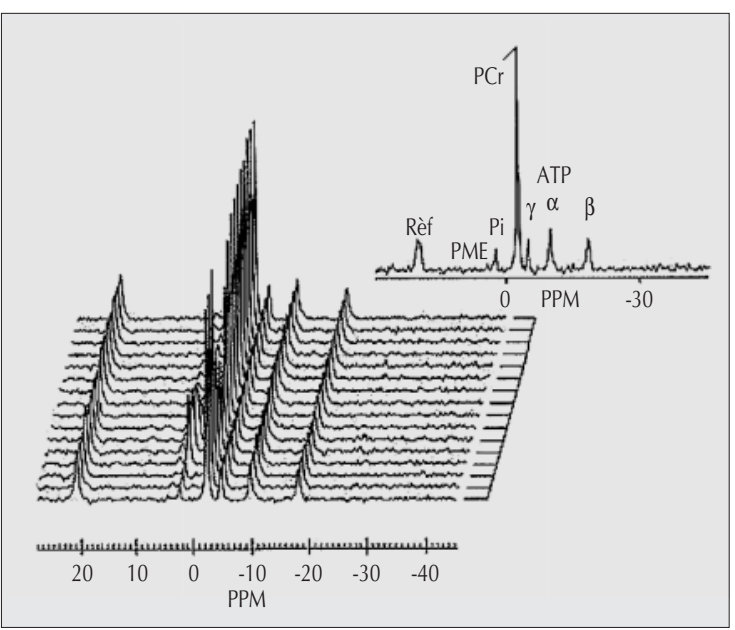

Figure 1 - A normal spectra of a forearm human muscle displaying 6 pics and their variation during a rest -exercice -recovery protocol. The major peaks of the Phosphorus-MR spectrum are: phosphocreatine $(\mathrm{PCr})$, inorganic phosphates (Pi), phosphodiesters (PDE), and the three peaks $(\alpha, \beta, \gamma)$ of ATP. The chemical shift (in parts per million [ppm]) of the $\mathrm{Pi}$ is used for calculation of intracellular, cytosolic $\mathrm{pH}$. Note the decrease of $\mathrm{PCr}$ concentration and the increase of $\mathrm{Pi}$ concentration during exercice.

the amount of the corresponding metabolite. The spectral distance between $\mathrm{Pi}$ and $\mathrm{PCr}$ provides information about intracellular $\mathrm{pH}(\mathrm{pHi})$ while the chemical shift of ATP can be used to calculate intracellular magnesium ion concentration. In living human muscle, only metabolites that are unbound and present at concentrations of at least $1 \mathrm{mM}$ give rise to peaks that have sufficient signal-to-noise ratio to be easily visible. The concentration of the metabolically active adenosine diphosphate (ADP), which is important in the regulation of rates of mitochondrial ATP synthesis, does not produce a signal visible in the spectra, but can be calculated indirectly using the creatine kinase $(\mathrm{CK})$ equilibrium equation. One of the most important features of ${ }^{31} \mathrm{P}-\mathrm{MRS}$ is its ability to monitor time-dependent changes of metabolites non invasively.

In normal exercising muscle, the hydrolysis of ATP releases the energy necessary for the sliding between myosin and actin proteins, the basis of muscle contraction. As a matter of consequence, one can observe in the MR spectra a PCr decrease stoechiometrically linked to $\mathrm{Pi}$ accumulation, while the ATP signal remains unchanged at least when exercise intensity is light or moderate.

This homeostatic system is due to the activation of different metabolic pathways successively activated to resynthesize ATP continuously: PCr hydrolysis, anaerobic glycolysis cascade then oxidative phosphorylation in mitochondria. During recovery from exercise, when no mechanical work is being done, glycolysis ceases but mitochondrial oxidative phosphorylation continues at an accelerated rate to replenish high-energy phosphate stores utilized during exercise. Thus, during recovery, $[\mathrm{PCr}]$ gradually increases, [Pi] and [ADP] decrease, and $\mathrm{pH}$ returns to its rest level (Fig. 2).
Figure 2 - Scheme of the variations of $\mathrm{PCr}, \mathrm{pH}$ and ATP during a rest-exercise-recovery protocol. Note that ATP remains constant during exercise in a normal subject due to its continuous resynthesis by three different metabolic pathways.

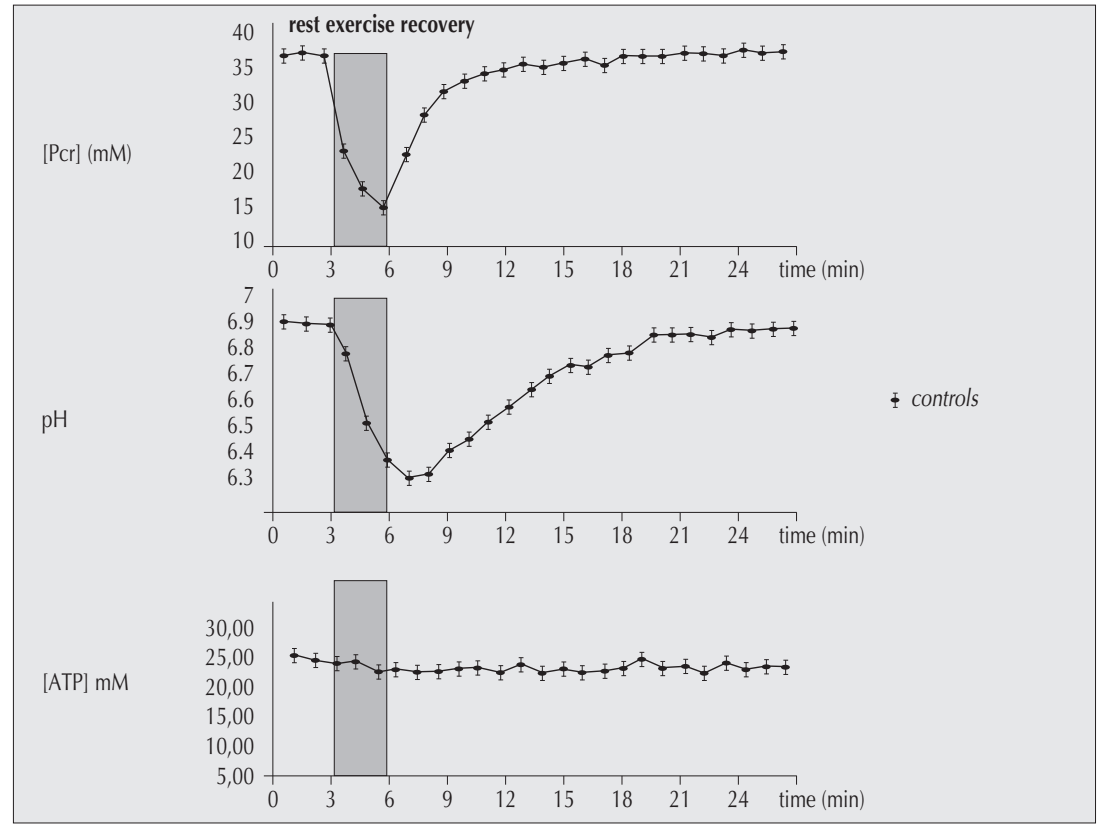


Table I - Summary of the changes of the main indices provided by P-31 MRS in metabolic myopathies.

\begin{tabular}{|c|c|c|c|c|c|c|c|c|c|}
\hline Protocol & & Rest & & & Exercise & & & Recovery & \\
\hline Metabolic parameters & {$[\mathrm{PCr}]$} & [Pi] & {$[\mathrm{PCr}] /[\mathrm{Pi}]$} & $\begin{array}{c}{[\mathrm{PCr}]} \\
\text { depletion }\end{array}$ & $\begin{array}{c}\mathrm{pH} \\
\text { variation }\end{array}$ & $\begin{array}{c}{[\mathrm{Pi}]} \\
\text { variation }\end{array}$ & $\mathrm{pH}$ & {$[\mathrm{PCr}]$} & {$[\mathrm{ADP}]$} \\
\hline $\begin{array}{l}\text { Mitochondrial } \\
\text { myopathies }\end{array}$ & decreased & increased & low & increased & acidosis & $\mathrm{N}$ & rapid & prolonged & prolonged \\
\hline Glycogenosis & $\mathrm{N}$ & $\mathrm{N}$ & $\mathrm{N}$ & increased & $\begin{array}{c}\text { No } \\
\text { acidosis }\end{array}$ & $\begin{array}{c}\text { Over- } \\
\text { production }\end{array}$ & $\mathrm{N}$ & $\mathrm{N}$ & $\mathrm{N}$ \\
\hline
\end{tabular}

Over the years different indices such as the rate of $\mathrm{PCr}$ decrease, the drop of $\mathrm{pH}$, the initial rate of $\mathrm{PCr}$ recovery and the recovery of ADP have been used in order to illustrate muscle energetics in vivo (4). The initial rate of $\mathrm{PCr}$ recovery provides a measure of maximal oxidative rate in the tissue and the recovery of ADP is now considered as one of the most sensitive and reliable index of mitochondrial dysfunction in vivo (5). Rates of ATP production by each metabolic pathway can also be quantitated, giving extraordinary insights of muscle metabolism in vivo (6).

During exercise, a large interindividual variability of metabolic changes is usually observed in humans and must be considered when using P-31MRS to explore pathological conditions. For example, the rates of PCr breakdown and recovery, as measured by $\mathrm{P}-31$ magnetic resonance spectroscopy, can differ by a factor of two among normal subjects (7). A normalization procedure is then required if reliable comparisons between patients and controls have to be made during exercise. Over the years, different methods have been used to take into account this high variability. Some of these methods consider anthropometric measurements like body mass index, lean bodymass $(8,9)$, muscle cross-sectional area $(10)$ or muscle volume (11) as normalization parameters; others use measurements of maximum voluntary contraction (12). An alternative strategy to capture individual differences is to find relationships among metabolic variables reflecting the intrinsic properties of muscle fibers. In our experience, relationships taking into account simultaneously work output and metabolic variables are the most appropriate. We have described criteria of metabolic normality reducing natural diversity and used them to compare healthy subjects and patients with muscular disorders $(13,14)$.

\section{P-31 MRS AS A DIAGNOSTIC TOOL}

Provided that this variability has been taken into account, P-31MRS can be used for diagnostic purposes in metabolic myopathies (Tab. I). These various diseases are mainly characterized by intolerance to muscle effort and/or by muscle fatigue. Their MRS semiology has now been perfectly described and we will present it briefly.

\section{Mitochondrial Disorders}

The clinical spectrum of mitochondrial disorders is large, due in part to their genetic and biochemical heterogeneity. A majority of these diseases include neurological symptoms besides muscle symptoms. However, in some cases muscle fatigue is the major symptom. These diseases can be suspected when an increase in serum of lactate and pyruvate is found, even at rest. The proportion of mutant versus wild-type mitochondrial DNA determines the biochemical phenotype. However, the link between the biochemical phenotype and the clinical phenotype is not always clear making the diagnosis difficult. Defects of respiratory chain enzymes are the most prevalent types of mitochondrial diseases. Their common endpoint is a deficit in ATP production leading to a decreased exercise tolerance and a shared pattern of detectable abnormalities.

At rest, a P-MRS spectrum of muscle from a patient with a mitochondrial myopathy most often shows an increase in $\mathrm{Pi}$, less often a decrease in $\mathrm{PCr}$ and as a result a low $\mathrm{PCr} / \mathrm{Pi}$ ratio. Although observations at rest are not specific of mitochondrial disorders, they can be very useful for very weak patients who cannot perform exercise in the magnet. During exercise, the consequence of a deficit in mitochondrial ATP production is an increase in nonoxidative energy production i.e., an increase of $\mathrm{PCr}$ consumption and glycolytic activity. Patients 
with mitochondrial myopathies display a rapid rate of PCr depletion during exercise (15-17). Despite lactic acidemia and low serum $\mathrm{pH}$, relative resistance to intracellular acidosis has been observed using MRS in exercising muscle of patients with mitochondrial diseases. The mechanism of this phenomenon may be related to the adaptation of intracellular buffering systems (including proton extrusion mechanisms) in response to chronic overproduction lactate (18).

During recovery, MRS measurements are the most sensitive and, overall, the most specific indices used to assess skeletal muscle mitochondrial rate of ATP production $(15-17,19,20)$. These indices include prolonged rate of $\mathrm{PCr}$ recovery, faster-thannormal $\mathrm{pH}$ recovery and a delay in post-exercise ADP recovery.

\section{Glycolytic Defects}

Deficits in carbohydrate metabolism can present either with exercise-induced symptoms such as painful cramps, contractures, and rhabdomyolysis or with progressive weakness. Muscles with impaired glycolysis or glycogenolysis lack the ability to produce lactic acid during exercise.

The most studied myopathy in this group was the myophosphorylase deficiency (McArdle disease). Patients experience a characteristic cramp at the beginning of exercise, later diminishing (the 'second wind' phenomenon). The lack of acidosis during exercise is directly detectable by P-31 MRS. An increased rate of $\mathrm{PCr}$ depletion and an overproduction of Pi are also apparent (21-24). The characteristic cramp was found to coincide with particularly high concentrations of ADP, a situation that develops at low [PCr] and high $\mathrm{pH}$ (22).

In other glycolytic pathologies, the overproduction of PME and their remanence during recovery suggest more distal disturbances of glycogenolysis, such as phosphofructokinase deficiency $(23,25-27)$.

\section{P-31 MRS AS A TOOL FOR PHYSIOPATHOLOGIC STUDIES}

Because MRS is well tolerated and examinations are easily repeated, the technique can also be employed in longitudinal studies of disease progression or the effects of treatment.

In dermatomyositis a high $\mathrm{Pi} / \mathrm{PCr}$ at rest and larger depletion of $\mathrm{PCr} / \mathrm{Pi}$ in the muscle of patients than normal subjects for similar percentage of maximal exercise load have been reported (28-31). P-31 MRS in- dices of muscle oxidative metabolism were all impaired in dermatomyositis and polymyositis The rate of proton efflux from muscle fibers was significantly reduced in these diseases suggesting an impaired blood supply (32). On the contrary, in polymyalgia rheumatica, we have demonstrated that there were no metabolic changes able to explain myalgia (33).

The technique has also become an important tool in the study of the pathophysiology of common systemic diseases such as renal or heart failure, peripheral vascular or thyroid disease which also influence muscle metabolism (3).

\section{P-31 MRS AS A TOOL FOR GENE FUNCTION STUDIES}

Magnetic resonance spectroscopy is being increasingly used in conjunction with other noninvasive technologies to investigate effects of gene function on metabolism. A recent example of such possibilities comes from the study of a protein called frataxin. Frataxin deficiency leads to the Friedreich ataxia, the most common of the inherited ataxias, which is associated to a severe defect of mitochondrial respiration through an intramitochondrial iron accumulation. The presence of a defect in mitochondrial metabolism in vivo was confirmed in vivo by P31 MRS and the deficit in Vmax for mitochondrial ATP production was found to correlate positively with the degree of genetic abnormality (34).

\section{P-31 MRS AS A TOOL IN THERAPEUTIC TRIALS}

More recently, P-31 MRS has been used as a measure of treatment response in therapeutic trials (3538). Unlike muscle biopsy, P-31 MRS can be used to repeatedly assess the response to therapy over long periods $(39,40)$. It has been used to supply evidence of therapeutic efficiency (or failure) in mitochondrial disorders treated by riboflavin and nicotinamide, (37) coenzyme Q10 $(18,36,41)$ dichloroacetate (35), and steroids(42).

\section{CONCLUSION}

P-31 MRS has now demonstrated its utility in the screening of metabolic myopathies even if certain myopathies such as AMP deaminase deficiency or carnityl palmityl transferase deficiency cannot be detected due to reduced or lack of abnormalities in 
energetic pathways. These diseases can be diagnosed by other type of investigations.

Despite these limitations, in a patient complaining of chronic muscle weakness or intolerance to exercise, especially if symptoms date back to childhood, P-31 MRS should be proposed as the first and pivotal investigation. If abnormalities are not detected, generally no other investigations are nec- essary. If abnormal metabolic changes are observed, a complete battery of tests including muscle biopsy must be proposed in order to make a diagnosis as accurate as possible.

P-31 MRS is also a potent tool to improve the comprehension of the physiopathology of a considerable number of diseases, which have a direct or indirect impact on muscle function and metabolism.

\section{SUMMARY}

${ }^{31} \mathrm{P}$ Magnetic Resonance Spectroscopy (MRS) is a potent tool allowing the investigation of muscle energetics in a noninvasive manner in humans. This review details the contribution of ${ }^{31} \mathrm{P}$ MRS to the diagnosis of metabolic myopathies and provides some clues for the use of this technique in a clinical perspective. Finally, the contribution of ${ }^{31} \mathrm{P}$ MRS to our understanding of the physiopathology of several other diseases is highlighted.

Key words - P-31 Magnetic Resonance Spectroscopy, human muscle, energy metabolism, metabolic myopathies, muscle diseases.

Parole chiave - Spettroscopia di risonanza magnetica P-31, muscolo, metabolismo energetico, miopatie metaboliche, malattie muscolari.

\section{REFERENCES}

1. Argov Z, Lofberg M, Arnold DL. Insights into muscle diseases gained by phosphorus magnetic resonance spectroscopy. Muscle Nerve 2000; 23: 1316-34.

2. Bendahan D, Mattei JP, Kozak-Ribbens G, Cozzone PJ. Non invasive investigation of muscle diseases using 31P magnetic resonance spectroscopy: potential in clinical applications. Rev Neurol (Paris) 2002; 158(5 Pt 1): 527-40.

3. Taylor DJ. Clinical utility of muscle MR spectroscopy. Semin Musculoskelet Radiol 2000; 4: 481-502.

4. Chance B, Eleff S, Leigh JS, Jr, Sokolow D, Sapega A. Mitochondrial regulation of phosphocreatine/inorganic phosphate ratios in exercising human muscle: a gated 31P NMR study. Proc Natl Acad Sci U S A 1981; 78: 6714-8.

5. Argov Z, De Stefano N, Arnold DL. ADP recovery after a brief ischemic exercise in normal and diseased human muscle: a 31P MRS study. NMR Biomed 1996; 9: 165-72.

6. Kemp GJ, Radda GK. Quantitative Interpretation of Bioenergetic Data from P-31 and H-1 Magnetic Resonance Spectroscopic Studies of Skeletal Muscle - An Analytical Review. Magn Reson Quart 1994; 10: 43-63.

7. Kushmerick M, Moerland T, Wiseman R. Mammalian skeletal muscle fibers distinguished by contents of phosphocreatine, ATP, and Pi. Proc Natl Acad Sci USA 1992; 89: 7521-5.

8. Lodi R, Kemp GJ, Muntoni F, Thompson CH, Rae C, Taylor $\mathrm{J}$ et al. Reduced cytosolic acidification during exercise suggests defective glycolytic activity in skeletal muscle of patients with Becker muscular dystrophy. An in vivo 31P magnetic resonance spectroscopy study. Brain 1999; 122(Pt 1): 121-30.

9. Lodi R, Taylor DJ, Tabrizi SJ, Hilton-Jones D, Squier
MV, Seller A et al. Normal in vivo skeletal muscle oxidative metabolism in sporadic inclusion body myositis assessed by 31P-magnetic resonance spectroscopy. Brain 1998; 121(Pt 11): 2119-26.

10. Nishida M, Nishijima H, Yonezawa K, Sato I, Anzai T, Okita K et al. Phosphorus-31 magnetic resonance spectroscopy of forearm flexor muscles in student rowers using an exercise protocol adjusted for differences in cross-sectional muscle area. Eur J Appl Physiol 1992; 64: 528-33.

11. Fowler M, Ryschon T, Wysong E, Combs A, Balaban R. Normalized metabolic stress for $31 \mathrm{P}-\mathrm{MR}$ spectroscopy studies of human skeletal muscle: MVC vs Muscle volume. J Appl Physiol 1997; 83: 875-83.

12. Larson-Meyer DE, Newcomer BR, Hunter GR, Hetherington HP, Weinsier RL. 31P MRS measurement of mitochondrial function in skeletal muscle: reliability, force-level sensitivity and relation to whole body maximal oxygen uptake. NMR Biomed 2000; 13: 14-27.

13. Bendahan D, Confort Gouny S, Kozak Ribbens G, Cozzone P. Heterogeneity of metabolic response to exercise in humans: new criteria of invariance defined by in vivo phosphorus NMR spectroscopy. FEBS Lett 1990; 272: 155-8.

14. Mattei JP, Kozak-Ribbens G, Roussel M, Le Fur Y, Cozzone PJ, Bendahan D. New parameters reducing the interindividual variability of metabolic changes during muscle contraction in humans. A 31P MRS study with physiological and clinical implications. Biochim Biophys Acta 2002; 1554: 129-36.

15. Arnold DL, Taylor DJ, Radda GK. Investigation of human mitochondrial myopathies by phosphorus magnetic resonance spectroscopy. Ann Neurol 1985; 18: 189-96.

16. Argov Z, Bank WJ, Maris J, Peterson P, Chance B. Bioenergetic heterogeneity of human mitochondrial 
myopathies: phosphorus magnetic resonance spectroscopy study. Neurology 1987; 37: 257-62.

17. Taylor DJ, Kemp GJ, Radda GK. Bioenergetics of skeletal muscle in mitochondrial myopathy. J Neurol Sci 1994; 127: 198-206.

18. Bendahan D, Desnuelle C, Vanuxem D, Confort-Gouny S, Figarella-Branger D, Pellissier JF et al. 31-P NMR spectroscopy and ergometer exercice test as evidence for muscle oxidative performance improvement with coenzyme Q in mitochondrial myopathies. Neurology 1992; 42: 1203-8.

19. Kuhl CK, Layer G, Traber F, Zierz S, Block W, Reiser M. Mitochondrial encephalomyopathy: correlation of P-31 exercise MR spectroscopy with clinical findings. Radiology 1994; 192: 223-30.

20. Matthews PM, Allaire C, Shoubridge EA, Karpati G, Carpenter S, Arnold DL. In vivo muscle magnetic resonance spectroscopy in the clinical investigation of mitochondrial disease. Neurology 1991; 41: 114-20.

21. Argov Z, Bank WJ, Maris J, Chance B. Muscle energy metabolism in McArdle's syndrome by in vivo phosphorus magnetic resonance spectroscopy. Neurology 1987; 37: 1720-4.

22. Ross BD, Radda GK, Gadian DG, Rocker G, Esiri M, Falconer-Smith J. Examination of a case of suspected McArdle's syndrome by $31 \mathrm{P}$ nuclear magnetic resonance. N Engl J Med 1981; 304: 1338-42.

23. Duboc D, Jehenson P, Tran Dinh S, Marsac C, Syrota A, Fardeau M. Phosphorus NMR spectroscopy study of muscular enzyme deficiencies involving glycogenolysis and glycolysis. Neurology 1987; 37: 663-71.

24. Bendahan D, Confort-Gouny S, Kozak-Ribbens G, Cozzone PJ. 31-P NMR characterization of the metabolic anomalies associated with the lack of glycogen phosphorylase activity in human forearm muscle. Biochem Biophys Res Commun 1992; 185: 16-21.

25. Argov Z, Bank WJ, Maris J, Leigh JS, Jr, Chance B. Muscle energy metabolism in human phosphofructokinase deficiency as recorded by $31 \mathrm{P}$ nuclear magnetic resonance spectroscopy. Ann Neurol 1987; 22: 46-51.

26. Argov Z, Bank WJ, Boden B, Ro YI, Chance B. Phosphorus magnetic resonance spectroscopy of partially blocked muscle glycolysis. An in vivo study of phosphoglycerate mutase deficiency. Arch Neurol 1987; 44: 614-7.

27. Vita G, Toscano A, Bresolin N, Meola G, Fortunato F, Baradello A et al. Muscle phosphoglycerate mutase (PGAM) deficiency in the first Caucasian patient: biochemistry, muscle culture and 31P-MR spectroscopy. J Neurol 1994; 241: 289-94.

28. Tarnopolsky MA, Parise G. Direct measurement of high-energy phosphate compounds in patients with neuromuscular disease. Muscle Nerve 1999; 22: 1228-33.

29. Park JH, Terri LV, Ryder NV. Magnetic resonance imaging and P-31 magnetic resonance spectroscopy provide unique quantitative data useful in the longitudinal management of patients with dermatomyositis. Arthritis Rheum 1994; 37: 736-46.

30. Park JH, Olsen NJ, King L, Vital T, Buse R, Kari S et al. Use of magnetic resonance imaging and P-31 reso- nance spectroscopy to detect and quantify muscle dysfunction in the amyopathic and myopathic variants of dermatomyositis. Arthritis Rheum 1995; 3: 68-77.

31. Park JH, Niermann KJ, Ryder NM, Nelson AE, Das A, Lawton AR et al. Muscle abnormalities in juvenile dermatomyositis patients: P-31 magnetic resonance spectroscopy studies. Arthritis Rheum 2000; 43: 2359-67.

32. Cea G, Bendahan D, Manners D. Reduced oxidative phosphorylation and proton efflux suggest reduced capillary blood supply in skeletal muscle of patients with dermatomyositis and polymyositis: a quantitative 31Pmagnetic resonance spectroscopy and MRI study. Brain 2002; 125(Pt 7): 1635-45.

33. Mattei JP, Bendahan D, Erkintalo M, Harle JR, Weiller PJ, Roux $\mathrm{H}$ et al. P-31 Magnetic resonance spectroscopy demonstrates unaltered muscle energy utilization in polymyalgia rheumatica. Arthritis Rheum 1997; 40: 1817-22.

34. Lodi R, Cooper JM, Bradley JL. Deficit of in vivo mitochondrial ATP production in patients with Friedreich ataxia. Proc Natl Acad Sci U S A 1999; 96: 11492-5.

35. De Stefano N, Matthews PM, Ford B, Genge A, Karpati G, Arnold DL. Short-term dichloroacetate treatment improves indices of cerebral metabolism in patients with mitochondrial disorders. Neurology 1995; 45: 1193-8.

36. Matthews PM, Ford B, Dandurand RJ, Eidelman DH, O'Connor D, Sherwin A et al. Coenzyme Q10 with multiple vitamins is generally ineffective in treatment of mitochondrial disease. Neurology 1993; 43: 884-90.

37. Penn AM, Lee JW, Thuillier P, Wagner M, Maclure KM, Menard MR et al. MELAS syndrome with mitochondrial tRNA (Leu) (UUR) mutation: correlation of clinical state, nerve conduction, and muscle $31 \mathrm{P}$ magnetic resonance spectroscopy during treatment with nicotinamide and riboflavin. Neurology 1992; 42: 2147-52.

38. Taivassalo T, Matthews PM, De Stefano N. Combined aerobic training and dichloroacetate improve exercise capacity and indices of aerobic metabolism in muscle cytochrome oxidase deficiency. Neurology 1996; 47: 529-34.

39. Argov Z, Bank WJ, Maris J, Eleff S, Kennaway NG, Olson RE et al. Treatment of mitochondrial myopathy due to complex III deficiency with vitamins K3 and C: A 31P-NMR follow-up study. Ann Neurol 1986; 19: 598-602.

40. Eleff S, Kennaway NG, Buist NR. 31P NMR study of improvement in oxidative phosphorylation by vitamins $\mathrm{K} 3$ and $\mathrm{C}$ in a patient with a defect in electron transport at complex III in skeletal muscle. Proc Natl Acad Sci USA 1984; 81: 3529-33.

41. Gold R, Seibel P, Reinelt G, Schindler R, Landwehr P, Beck A et al. Phosphorus magnetic resonance spectroscopy in the evaluation of mitochondrial myopathies: results of a 6-month therapy study with coenzyme Q. Eur Neurol 1996; 36: 191-6.

42. Heiman-Patterson TD, Argov Z, Chavin JM, Kalman B, Alder H, DiMauro S et al. Biochemical and genetic studies in a family with mitochondrial myopathy. $\mathrm{Mu}-$ scle Nerve 1997; 20: 1219-24. 